\title{
Supraventricular tachycardia as initial manifestation of polymyositis. Case report
}

\section{Taquicardia supraventricular como manifestación inicial de polimiositis. Reporte de caso}

\author{
Jorge E. Reyes-Tovilla1,2, ${ }^{1,}$, Fabio Solis-Jiménez ${ }^{1,2}$, and César L. González-Aguilar ${ }^{1,3}$ \\ ${ }^{1}$ Internal Medicine Department, Hospital General de Mexico "Dr. Eduardo Liceaga", Faculty of Medicine, Universidad Nacional Autónoma de México; \\ ${ }^{2}$ Instituto Nacional de Cardiología "Ignacio Chávez"; ${ }^{3}$ Centro Médico Nacional "20 de Noviembre", Universidad Nacional Autónoma de México, \\ Mexico City, Mexico
}

Inflammatory myopathies are a group of skeletal muscle autoimmune diseases that can affect other organs and systems, such as the cardiovascular system ${ }^{1}$, with the most affected being the myocardium, due to coronary artery atherosclerosis. Rhythm abnormalities such as supraventricular tachycardia are rare and occur in $0.9 \%$ of cases, with the most common being conduction system disorders such as bundle branch blocks and repolarization abnormalities ${ }^{2}$. We present the case of a 41-year-old man with no relevant history. He was admited for sudden onset chest pain, which had started one hour prior. Narrow QRS tachycardia with long RP interval (Fig. 1) was documented, which was reverted with adenosine, and, subsequently, sinus rhythm with right bundle branch block was documented (Fig. 2). At Internal Medicine Department, inflammatory myopathy diagnostic workup was initiated; on physical examination, proximal weakness of neck and limbs muscles was observed; in addition, muscle enzymes elevation was documented (CK: 2,090 U/L). Auto-antiantibodies determination reported: antinuclear antibodies 1:160 cytoplastic pattern; anti-Jo-1, $0.52 \mathrm{U} / \mathrm{mL}$; anti-Ro52, $150 \mathrm{U} / \mathrm{mL}$; troponin I, $0.47 \mathrm{pg} / \mathrm{mL}$; MB isoenzyme, $89 \mathrm{U} / \mathrm{L}$; and B-type natriuretic peptide, $1,261 \mathrm{pg} / \mathrm{mL}$. Transthoracic echocardiogram revealed $65 \%$ left ventricular ejection fraction; right ventricular systolic pressure, 35; tricuspid annular plane systolic excursion (TAPSE), 15; tricuspid S-wave, $9 \mathrm{~cm} / \mathrm{s}$. On muscle biopsy, atrophic muscle fibers and myocytes with centralized nucleus were observed. Neuroconduction velocities with repetitive complex discharges, fibrillation potentials and positive waves. Spirometry (Fig. 3) and chest tomography (Fig. 4) were performed due to suspected interstitial lung disease. The patient met Bohan and Peter criteria for polymyositis and was started on methotrexate, prednisone, metoprolol and propafenone. Rhythm abnormalities are an atypical presentation of polymyositis and few studies have been conducted to know their prevalence ${ }^{2,3}$. No morphological alterations were found on echocardiogram at the time of presentation in a study with 30 patients $^{4}$; however, in our case, only TAPSE was altered. Autoimmune disease pro-inflammatory state could be associated with rhythm abnormalities, but many studies are still required to substantiate this situation; supraventricular tachycardia is an atypical manifestation in polymyositis.

\section{Acknowledgements}

To our families, to Juan D. Muñoz, Alejandra Aquino and the institution for the support during these four years of internal medicine residency.
Correspondence:

*Jorge E. Reyes-Tovilla

E-mail: drjert88@gmail.com
Available online: 19-07-2021 Arch Cardiol Mex (Eng). 2021;91(2):203-205 www.archivoscardiologia.com 2604-7063 / @ 2020 Instituto Nacional de Cardiología Ignacio Chávez. Published by Permanyer. This is an open access article under the CC BY-NC-ND license (http://creativecommons.org/licenses/by-nc-nd/4.0/). 


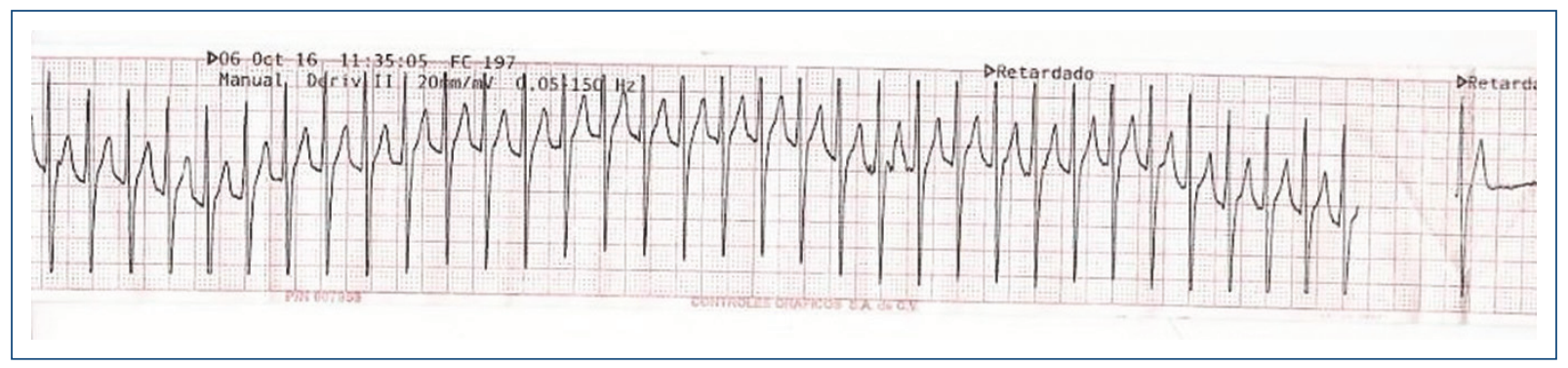

Figure 1. Electrocardiogram lead II strip at admission.

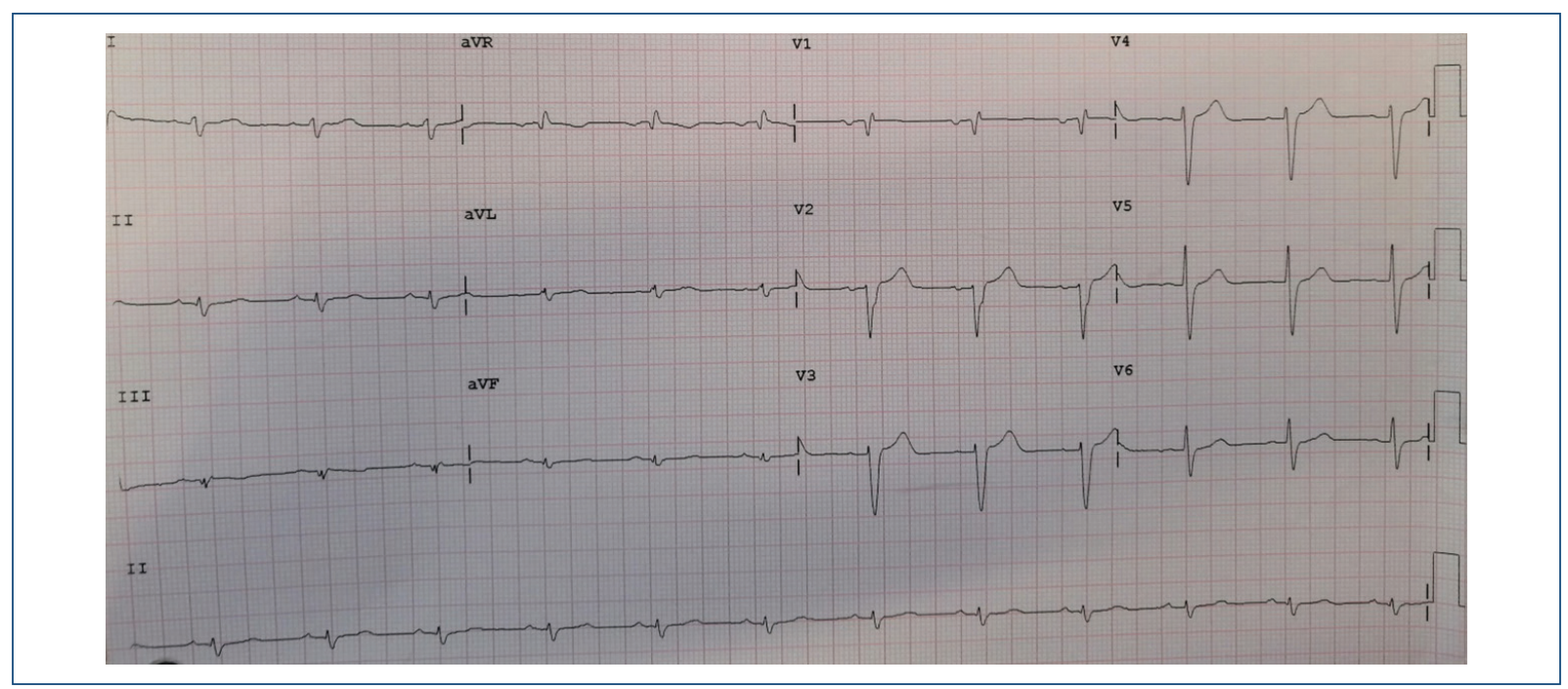

Figure 2. 12-lead electrocardiogram after adenosine.

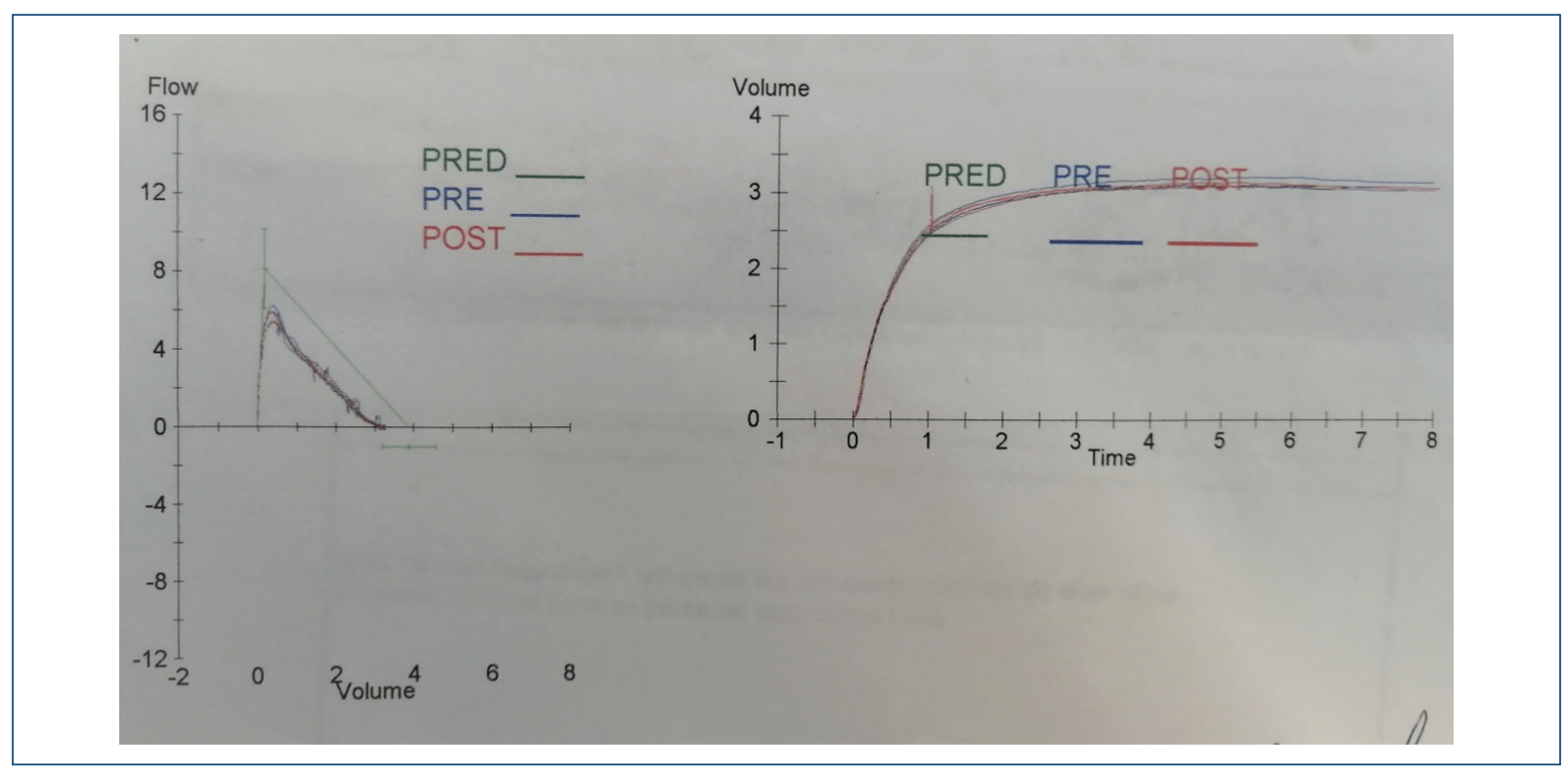

Figure 3. Spirometry suggesting moderate restriction with response to bronchodilator. 


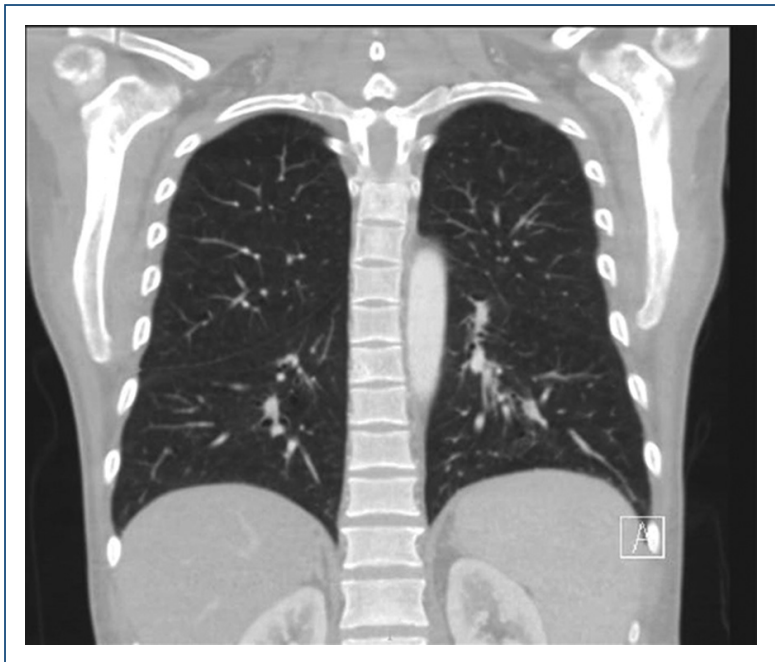

Figure 4. High-resolution tomography. Axial section, pulmonary window, suggestive of interstitial lung disease.

\section{Funding}

Funding granted by Hospital General de México "Dr. Eduardo Liceaga".

\section{Conflicts of interest}

The authors declare that they have no conflicts of interest.

\section{Ethical disclosures}

Protection of human and animal subjects. The authors declare that no experiments have been performed on humans or animals for this research.

Confidentiality of data. The authors declare that they have followed the protocols their of their work center on the publication of patient data.

Right to privacy and informed consent. The authors declare that no patient data appear in this article.

\section{References}

1. Danieli MG, Gelardi C, Guerra F, Cardinaletti P, Pidini V, Gabrielli A. Cardiac involvement in polymyositis and dermatomyositis. Autoimmun Rev. 2016:15(5):462-5.

2. Deveza LM, Miossi R, de Souza FH, Shimabuco AY, Favarato $M H$ Grindler J, et al. Electrocardiographic changes in dermatomyositis and polymyositis. Rev Bras Reumatol Engl Ed. 2016;56(2):95-100.

3. Stern R, Godbold JH, Chess Q, Kagen LJ. ECG abnormalities in polymyositis. Arch Intern Med. 1984;144(11):2185-9.

4. Péter A, Balogh A, Szilágyi S, Faludi R, Nagy-Vincze M, Édes I, et al Echocardiographic abnormalities in new-onset polymyositis/dermatomyositis. J Rheumatol. 2015;42(2):272-81. 